\title{
Apigenin induces both intrinsic and extrinsic pathways of apoptosis in human colon carcinoma HCT-116 cells
}

\author{
BO WANG ${ }^{1,2}$ and XIN-HUAI ZHAO ${ }^{1}$ \\ ${ }^{1}$ Key Laboratory of Dairy Science, Ministry of Education, Northeast Agricultural University, Harbin, Heilongjiang 150030; \\ ${ }^{2}$ College of Pharmacy, Heilongjiang University of Chinese Medicine, Harbin, Heilongjiang 150040, P.R. China
}

Received July 1, 2016; Accepted November 24, 2016

DOI: $10.3892 /$ or.2016.5303

\begin{abstract}
Apigenin is one of the plant-originated flavones with anticancer activities. In this study, apigenin was assessed for its in vitro effects on a human colon carcinoma line (HCT-116 cells) in terms of anti-proliferation, cell cycle progression

Correspondence to: Professor Xin-Huai Zhao, Key Laboratory of Dairy Science, Ministry of Education, Northeast Agricultural University, 59 Mucai Street, Harbin, Heilongjiang 150030, P.R. China E-mail: zhaoxh@neau.edu.cn
\end{abstract}

Abbreviations: AKT, RAC- $\alpha$ serine/threonine-protein kinase; Apaf-1, apoptotic peptidase activating factor 1; ATF3, activating transcription factor 3; Bak, Bcl-2 antagonist/killer; Bax, Bcl-2 associated $\mathrm{x}$ protein; Bcl-2, B-cell cll/lymphoma 2; Bcl-w, Bcl-2-like protein 2; Bcl-xl, B-cell lymphoma-extra large; BID, BH3 interacting domain death agonist; Bok, Bcl-2-related ovarian killer; CCK-8, Cell Counting Kit-8; cDNA, complementary DNA; CHOP, C/EBP homologous protein; COX IV, cytochrome c oxidase IV; DCF-DA, 2',7'-dichloro-fluorescein; DMSO, dimethyl sulphoxide; DPBS, Dulbecco's phosphate-buffered saline; DR3, death receptor 3; DR4, death receptor 4; DR5, death receptor 5; EGTA, ethylene glycol tetraacetic acid; ER, endoplasmic reticulum; FADD, FAS-associating death domain-containing protein; FAS, cell surface death receptor; FasL, fas ligand; 5-Fu, 5-fluorouracil; Fura-2 Am, Fura-2 pentakis (acetoxymethyl) ester; HEPES, 4-(2-hydroxyethyl)1-piperazineethanesulfonic acid; Id1, inhibitor of DNA binding 1; JAK2, janus kinase 2; JC-1, 5,5',6,6'-tetrachloro-1,1',3,3'-tetraethyl benzimidazolocarbocyanine iodide; MAPK, mitogen-activated protein kinase; Mcl-1, myeloid cell leukemia 1; MMP, mitochondrial membrane potential; NAC, $\mathrm{N}$-acetyl cysteine; $\mathrm{NF \kappa B}$, nuclear factor $\kappa \mathrm{B}$ subunit; PARP, poly-(ADP-ribose) polymerase; PBS, phosphate buffer saline; PI, propidium iodide; PKC $\delta, C$ Protein kinase $C \delta$ type; PTP, permeability transition pore; qRT-PCR, quantitative real-time PCR; RIPA, radio immunoprecipitation assay; RNS, reactive nitrogen species; ROS, reactive oxygen species; STAT3, signal transducer and activator of transcription 3; TNFR1, tumor necrosis factor receptor-1; tBID, truncated BID; TRAIL, tumor necrosis factor-related apoptosis-inducing ligand; UPR, unfolded protein response; VEGF, vascular endothelial growth factor $\mathrm{A}$

Key words: apigenin, human colon carcinoma cells, cytotoxic effect, apoptotic mechanism, reactive oxygen species, endoplasmic reticulum stress arrest, apoptosis and intracellular reactive oxygen species (ROS) generation, and then outlined its possible apoptotic mechanism for the cells. Apigenin exerted cytotoxic effect on the cells via inhibiting cell growth in a dose-time-dependent manner and causing morphological changes, arrested cell cycle progression at $\mathrm{G}_{0} / \mathrm{G}_{1}$ phase, and decreased mitochondrial membrane potential of the treated cells. Apigenin increased respective ROS generation and $\mathrm{Ca}^{2+}$ release and thereby, caused ER stress in the treated cells. Apigenin shows apoptosis induction towards the cells, resulting in enhanced portion of apoptotic cells. A mechanism involved ROS generation and endoplasmic reticulum stress was outlined for the apigeninmediated apoptosis via both intrinsic mitochondrial and extrinsic pathways, based on the assayed mRNA and protein expression levels in the cells. With this mechanism, apigenin resulted in the HCT-116 cells with enhanced intracellular ROS generation and $\mathrm{Ca}^{2+}$ release together with damaged mitochondrial membrane, and upregulated protein expression of CHOP, DR5, cleaved BID, Bax, cytochrome c, cleaved caspase-3, cleaved caspase- 8 and cleaved caspase- 9 , which triggered apoptosis of the cells.

\section{Introduction}

Apigenin (4',5,7-trihydroxy-flavone) is a plant-derived flavonoid compound, and is ubiquitously found in both fruits and vegetables. Besides its anti-inflammatory, anti-oxidant and anticancer properties $(1,2)$, apigenin has received particular interest as a cancer chemopreventive agent for a variety of cancers in recent years. Apigenin inhibits the proliferation of the A2780 ovarian cancer cells in a dose-time-dependent manner through overexpression of ATF3 to suppress Id1 expression (3). Apigenin possesses anti-growth activity on both the prostate (DU-145) and breast (MDA-MB-231) cancer cells through caspase- 3 activation mediated by estrogen receptor (ER)- $\beta$ (4). Apigenin at $60 \mu \mathrm{M}$ induces apoptosis in the human promyelocytic leukaemia HL-60 cells via mitochondria dysfunction releasing cytochrome $\mathrm{c}$ to active caspase-3, caspase- 9 and cleavage of poly-(ADPribose) polymerase (PARP) (5).

In the eukaryotic cells, protein molecules spontaneously fold during or after biosynthesis to form biologically functional conformation. Failure to fold into native three-dimensional structure generally leads to inactive proteins $(6,7)$. The 
endoplasmic reticulum (ER) is the major organelle for protein biosynthesis, folding, maturation and translocation (8). When cells are stimulated, unfolded proteins accumulate in the lumen of ER. Dis-homeostasis of ER results in a pathological response known as ER stress. The organelle has its unique signaling pathways to overcome ER stress, such as i) slowing down translational rate to prevent further accumulation of the mis-folded proteins; ii) upregulating the genes capable of increasing the protein-folding capacity in ER; iii) activating the NFאB to trigger immune and anti-apoptotic responses; and iv) inducing apoptosis (9). When ER organelle is severely impaired, apoptosis is provoked to eliminate the damaged cells notably through upregulating the expression of a sensor protein, C/EBP homologous protein (CHOP) (9). Under nonstressed conditions, CHOP expresses at low level; however, when cells are under adverse conditions (e.g. glucose deprivation, amino acid starvation and ER stress), CHOP will be overexpressed to disturb cell cycle progression (10). CHOP can activate downstream protein expression by upregulating the pro-apoptotic proteins (e.g. Bax and Bak) and by downregulating the anti-apoptotic proteins (e.g. Bcl-2 and Bcl-xl) to induce the intrinsic pathway, and can also upregulate downstream the pro-apoptotic death receptor 5 (DR5) to induce the extrinsic pathway (11).

Intracellular-free radicals such as reactive oxygen species (ROS) and reactive nitrogen species (RNS) are related with ER stress, mitochondria dysfunction and inflammation (12). In general, intracellular ROS levels are relatively low. When cells are exposed to stimuli, intracellular ROS generation increases. Although ROS can promote cell proliferation and differentiation, excessive ROS cause oxidative stress, which is harmful to cells (13). However, in cancer cells, increase of ROS generation is related with apoptosis (14-16). ROS at the same level can kill cancer cells without any significant toxicity to their normal counterparts (17). Increasing evidence shows that overload ROS will cause ER stress. For example, auranofin can induce ROS-mediated ER stress and mitochondrial dysfunction via upregulating CHOP expression and cleaving caspase-3 and PARP in the human gastric cancer cells, BGC-823 and SGC-7901 (18). Sarsasapogenin from a Chinese medical herb Anemarrhena asphodeloides Bunge causes both significant intracellular ROS generation and $\mathrm{CHOP}$ expression in the HeLa cells (19). However, if an anti-oxidant N-acetyl cysteine (NAC) is used to treat the cells before sarsasapogenin application, the amounts of ROS (together with ER stress and apoptosis) decrease, implying that sarsasapogenin-induced ER stress and mitochondria dys-function are triggered by ROS generation (19).

Pre-treatment of the MIA PaCa-2 cells with NAC will markedly decrease intracellular ROS generation induced by a synthesized polyphenol conjugate (E)-3-(3,5-dimethoxyphenyl)1-(2-methoxyphenyl)prop-2-en-1-one (DPP-23), along with reduced expression of the UPR (unfolded protein response) proteins (GRP78/BiP, IRE1a, and CHOP) (20). This indicates that intracellular ROS production is upstream of the ER stress-mediated apoptosis (20). Iso-obtusilactone A isolated from Cinnamomum kotoense can increase intracellular ROS generation, and upregulate CHOP and DR5 protein levels in the hepatoma Hep G2 cells; however, pre-treatment the cells with NAC can decrease ROS generation associated with lower expression levels of the two apoptotic-related proteins (21). It is thus proved that much ROS production is able to provoke ER stress-mediated apoptosis towards cancer cells.

To obtain more evidence on anticancer potential of apigenin, this study aimed to verify its in vitro effects on a human colon carcinoma line (HCT-116 cells), and to outline a possible apoptotic mechanism involving both intracellular ROS generation and ER stress.

\section{Materials and methods}

Chemicals and reagents. Apigenin with purity $>99 \%$ was purchased from Shanghai Yousi Biotechnology Co. Ltd. (Shanghai, China). Cell Counting Kit-8 (CCK-8), cell cycle analysis kit, Annexin V-FITC apoptosis detection kit, Hoechst 33258 , ROS assay kit, mitochondrial membrane potential assay kit with JC-1, Fura-2 pentakis (acetoxymethyl) ester (Fura-2 Am), radio immunoprecipitation assay (RIPA) lysis buffer and BCA protein assay kit were purchased from Beyotime Institute of Biotechnology (Shanghai, China). TRNzol Universal Reagent, TIANScript RT kit and Real Master Mix (SYBR Green) were purchased form Tiangen Biotech, Co. Ltd. (Beijing, China). Other chemicals used were of analytical grade. Water used was generated from Milli-Q Plus system (Millipore, New York, NY, USA).

Cells and antibodies. The cell line (HCT-116) used in this study was obtained from the Cell Bank of Shanghai Institute of Biochemistry and Cell Biology (Shanghai, China). The cells were cultured in McCoy's 5A medium (Sigma-Aldrich, Co. St. Louis, MO, USA) supplemented with $10 \%$ of fetal bovine serum (Hyclone, Logan, UT, USA) at $37^{\circ} \mathrm{C}$ in $5 \% \mathrm{CO}_{2}$ atmosphere, as recommended by the cell supplier.

Primary antibodies CHOP, DR5, cytochrome c oxidase IV (COX IV), cytochrome c, Bax, BID, cleaved caspase-3, -8, and -9 , as well as secondary antibodies were provided by Cell Signaling Technology (Shanghai) Biological Reagents Co., Ltd. (Shanghai, China).

Assay of cell viability. The cells were seeded at a density of $1 \times 10^{4}$ cells per $100 \mu \mathrm{l}$ per well onto the 96-well plates. After cell attachment, the medium was discarded. Dimethyl sulphoxide (DMSO, negative control) of $0.1 \%, 5$-fluorouracil (5-Fu, positive control) of $100 \mu \mathrm{M}$, and apigenin of $40-160 \mu \mathrm{M}$ were added to treat the cells for 24,48 and $72 \mathrm{~h}$, respectively. After that, the solutions were discarded, and the cells were washed twice by a phosphate buffer saline (PBS, $0.01 \mu \mathrm{M}$, $\mathrm{pH}$ 7.0). CCK-8 solution of $10 \mu \mathrm{l}$ was added into each well to make a final concentration of $10 \%$. The plates were then incubated at $37^{\circ} \mathrm{C}$ for another $4 \mathrm{~h}$. A microplate reader (Bio-Rad Laboratories, Hercules, CA, USA) was used to measure the absorbencies at $570 \mathrm{~nm}$. The vehicle-treated cells were taken as $100 \%$ viable. The growth inhibition of the cells was thus calculated as previously described (22).

Morphological observation. The cells $\left(1 \times 10^{4}\right.$ cells per $100 \mu \mathrm{l}$ per well) were seeded onto 6-well plates for attachment, treated by $0.1 \%$ DMSO, $40-160 \mu \mathrm{M}$ apigenin for $24 \mathrm{~h}$, rinsed with the PBS twice, followed by the treatment of $0.5 \mathrm{ml}$ of paraformaldehyde (4\%) in the PBS at $4^{\circ} \mathrm{C}$ overnight to fix the 
cells. The cells were washed with the PBS twice, stained with Hoechst 33258 of $0.5 \mathrm{ml}$ for $5 \mathrm{~min}$ at room temperature in the dark, and then rinsed with the PBS twice. The stained cells were observed and photographed under a fluorescence microscope (Olympus, Tokyo, Japan) with respective excitation and emission wavelengths of 350 and $460 \mathrm{~nm}$.

Assay of cell cycle progression. After $24 \mathrm{~h}$ of treatment with $0.1 \%$ DMSO or $60-160 \mu \mathrm{M}$ apigenin, the cells were harvested and washed with the PBS. Ice-cold $70 \%$ ethanol was added to fix the cells at $4^{\circ} \mathrm{C}$ overnight. After that, the cells were rinsed with the ice-cold PBS, and incubated with $25 \mu 1$ propidium iodide (PI, $50 \mu \mathrm{g} / \mathrm{ml})$ and $10 \mu \mathrm{l} \mathrm{RNase}(100 \mu \mathrm{g} / \mathrm{ml})$ for $30 \mathrm{~min}$ at $37^{\circ} \mathrm{C}$ in the dark. Flow cytometric cell analysis was performed using a BD FACSort flow cytometry (Becton Dickson Immunocytometry-Systems, San Jose, CA, USA). CellQuest software (ModFit software, Verity Software House, Inc., Topsham, ME, USA) was used to determine the portions of the cells in different cell stages of cell cycle progression $\left(\mathrm{G}_{0} / \mathrm{G}_{1}, \mathrm{~S}\right.$, and $\mathrm{G}_{2} / \mathrm{M}$ phases $)$.

Apoptosis analysis by flow cytometry. The cells treated with $0.1 \%$ DMSO or $60-160 \mu \mathrm{M}$ apigenin in the 6-well plates were harvested after $24 \mathrm{~h}$, and washed twice with the ice-cold PBS. Double staining with FITC-Annexin V and PI was carried out using the Annexin V-FITC Apoptosis Detection kit according to the manufacturer's protocol. Briefly, the cells were incubated with $5 \mu \mathrm{l}$ of the Annexin V-FITC and $10 \mu \mathrm{l}$ of PI $(20 \mu \mathrm{g} / \mathrm{ml})$ at room temperature for $20 \mathrm{~min}$ in the dark. The cells were then discriminated into viable, necrotic, early apoptotic, and late apoptotic cells, using flow cytometry and CellQuest software as above.

Detection of mitochondrial membrane potential, intracellular ROS and $\mathrm{Ca}^{2+}$. The cells $\left(1 \times 10^{6}\right.$ per chamber) were treated with DMSO $(0.1 \%$, control) and apigenin of $60-160 \mu \mathrm{M}$ for $24 \mathrm{~h}$. Afterward, the cells were re-suspended in fresh medium, and incubated with the JC-1 (5,5',6,6'-tetrachloro-1,1',3,3'tetraethyl benzimidazolocarbocyanine iodide) of $1 \mathrm{ml}$ at $37^{\circ} \mathrm{C}$ for $20 \mathrm{~min}$. The cells were rinsed with Dulbecco's phosphate-buffered saline (DPBS) twice, and re-suspended in $2 \mathrm{ml}$ medium. The loss of mitochondrial membrane potential (MMP) was evaluated by the flow cytometry with respective excitation and emission wavelengths of 485 and $590 \mathrm{~nm}$ as previously described (23).

For the assay of intracellular ROS, the cells were treated with $0.1 \%$ DMSO or $60-160 \mu \mathrm{M}$ apigenin for $24 \mathrm{~h}$ at $37^{\circ} \mathrm{C}$, followed by two washes with the PBS. Then, $1 \mathrm{ml}$ of DCF-DA (2',7'-dichlorofluorescein, $10 \mu \mathrm{M}$ ) were added into each well, and the cells were re-incubated at $37^{\circ} \mathrm{C}$ for another $20 \mathrm{~min}$. The cells were rinsed with the fresh medium three times. Fluorescence intensities were detected by a fluorescence spectrophotometer (F-4500, Hitachi, Tokyo, Japan) at 488/525 nm with a $525 \mathrm{~nm}$ cut-off (24).

The cells were seeded overnight and then applied with $0.1 \%$ DMSO or $60-160 \mu \mathrm{M}$ apigenin at $37^{\circ} \mathrm{C}$ for $24 \mathrm{~h}$. The cells were collected and rinsed with the Krebs-Ringer buffer (pH 7.4), which contained $137 \mathrm{mM} \mathrm{NaCl}, 5 \mathrm{mM} \mathrm{KCl,} 1 \mathrm{mM}$ $\mathrm{MgCl}_{2}, 1.5 \mathrm{mM} \mathrm{CaCl} 2,10 \mathrm{mM}$ 4-(2-hydroxyethyl)-1-piperazineethanesulfonic acid (HEPES), and $25 \mathrm{mM}$ D-glucose. The

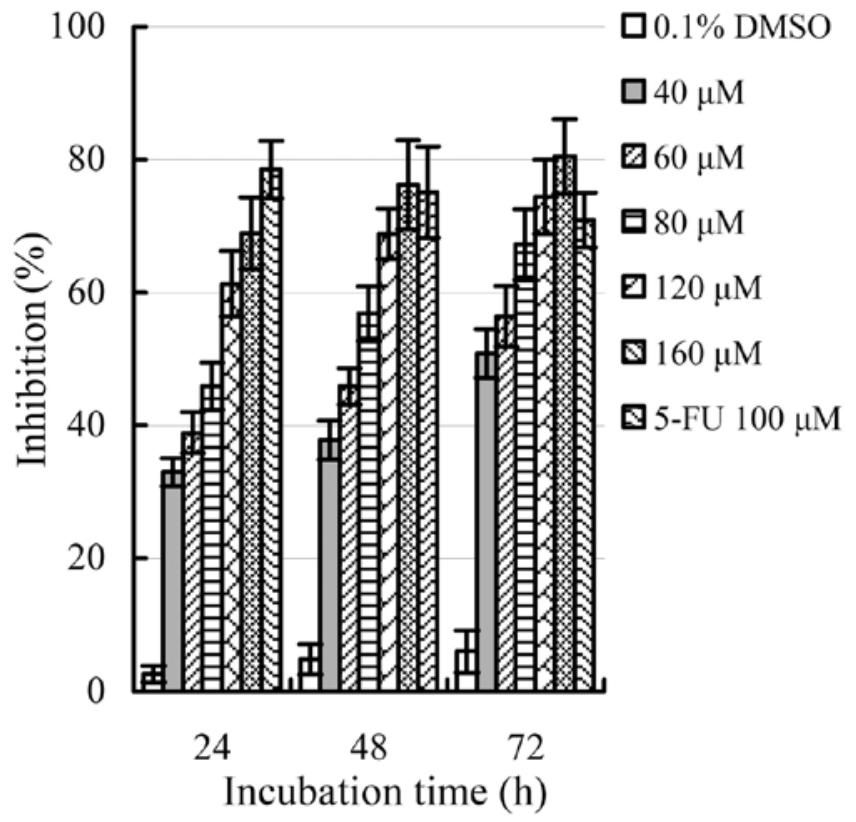

Figure 1. Effects of apigenin doses on the growth of the HCT-116 cells. The cells were exposed to $0.1 \%$ DMSO (negative control), 40-160 $\mu \mathrm{M}$ apigenin, and $100 \mu \mathrm{M}$ 5-fluorouracil (positive control) for 24-72 h, respectively.

cells were collected and incubated with the Fura-2 AM $(5 \mu \mathrm{M})$ at $37^{\circ} \mathrm{C}$ for $60 \mathrm{~min}$. After that, the cells were washed twice and re-suspended in the Krebs-Ringer buffer, and measured for fluorescence $\left(F_{s}\right)$. The used emission and excitation wavelengths were 510 and 340-380 nm, respectively. The cells treated with $0.1 \%$ of Triton X-100 (v/v) were used to determine the maximal fluorescence $\left(F_{\text {max }}\right)$, followed by addition of $10 \mathrm{mM}$ EGTA (ethylene glycol tetra-acetic acid, $\mathrm{pH} 9.0$ ) to determine the minimal fluorescence $\left(F_{\min }\right)$. Intracellular $\mathrm{Ca}^{2+}$ $\left(\left[\mathrm{Ca}^{2+}\right]_{\mathrm{i}}\right)$ was calculated using following equation as $\left[\mathrm{Ca}^{2+}\right]_{\mathrm{i}}=k_{d}$ $\left(F_{s}-F_{\min }\right) /\left(F_{\max }-F_{s}\right)$, in which $k_{d}$ has a value of $224 \mathrm{nM}(25)$.

Isolation of mRNAs and quantitative real-time $P C R$ ( $q R T-P C R)$. Total RNA of the HCT-116 cells was extracted with the TRNzol Universal Reagent (Tiangen Biotech, Co. Ltd.), and complementary DNA (cDNA) was then reverse transcribed using the TIANScript RT kit and the protocol provided by the kit manufacturer. The qRT-PCR was performed using a 7500 Real-Time PCR System (Applied Biosystems, Foster City, CA, USA). cDNA of $1 \mu \mathrm{l}$ was added to $9 \mu \mathrm{l}$ of $2.5 \mathrm{X}$ Real Master Mix (20X SYBR Green) containing $5 \mu \mathrm{l}$ of each of the corresponding primer pairs to make a final system volume of $20 \mu \mathrm{l}$ for each well. Thermo-cycling conditions were used as follows: initial activation for $1 \mathrm{~min}$ at $95^{\circ} \mathrm{C}$, followed by 40 cycles of denaturation at $95^{\circ} \mathrm{C}$ for $15 \mathrm{sec}$, annealing for $20 \mathrm{sec}$ at $60^{\circ} \mathrm{C}$ and extension for $32 \mathrm{sec}$ at $68^{\circ} \mathrm{C}$. The fluorescence was measured during the extension step. Relative expression levels of the target genes were determined using the $2^{-\Delta \Delta \mathrm{Ct}}$ method (26). The $\beta$-actin housekeeping gene was used as an internal control. The used primers were designed with the sequences below, and synthesized by Sangon Biotech (Shanghai) Co., Ltd. (Shanghai, China). i) human $\beta$-actin forward, 5'-AACACCCCAGCCATGTACG-3' and reverse, 5'-ATGTCACGCACGATTTCCC-3'; ii) CHOP forward, 5'-GCCAATGATGTGACCCTCAAT-3' and reverse, 5'-CCTGGAAATGAAGAGGAAGAA-3'; iii) DR5 

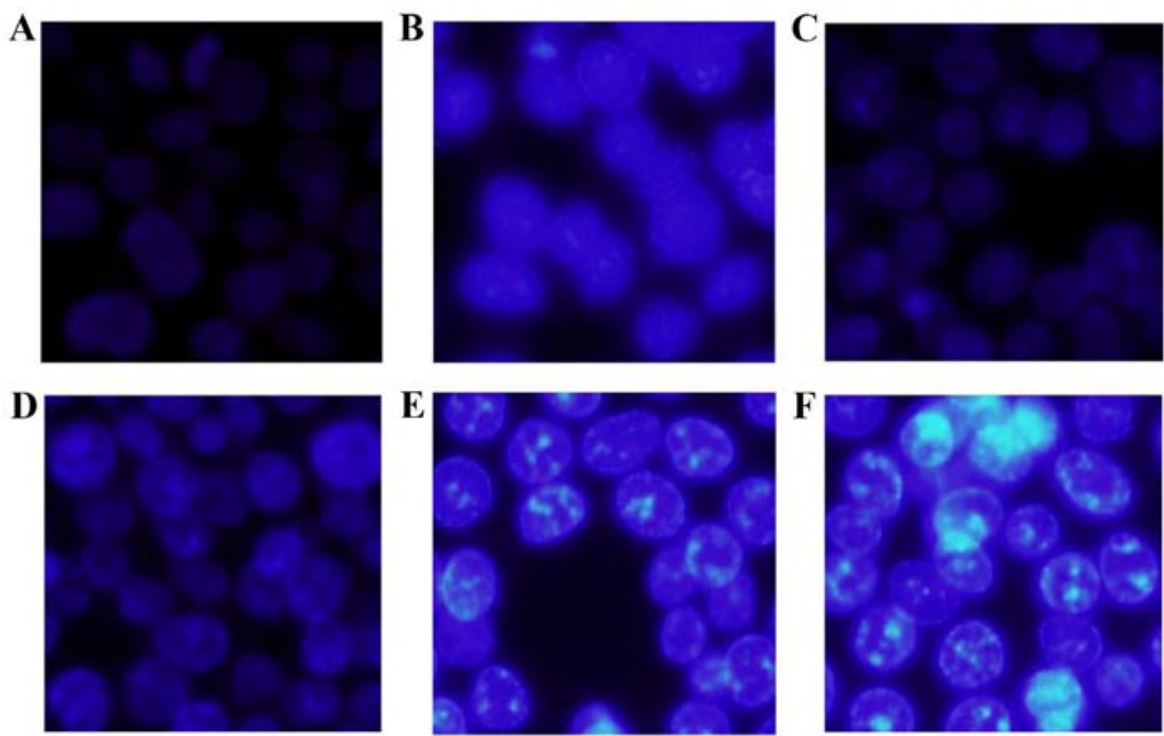

Figure 2. Morphological changes of the HCT-116 cells exposed to apigenin. Apoptotic-like cells show shrinkage, condensed domain and apoptotic bodies. (A-F) represents the control cells, and the cells treated by apigenin of $40,60,80,120$, and $160 \mu \mathrm{M}$, respectively.

forward, 5'-AAGACCCTTGTGCTCGTTGT-3' and reverse, 5'-GACACATTCGATGTCACTCCA-3'.

Western blot assay. After $24 \mathrm{~h}$ treatment with $0.1 \%$ DMSO or $60-160 \mu \mathrm{M}$ apigenin at $37^{\circ} \mathrm{C}$ for $24 \mathrm{~h}$, the cells were harvested and lysed with the RIPA lysis buffer, followed by a centrifugation at $14,000 \mathrm{xg}$ at $4^{\circ} \mathrm{C}$ for $10 \mathrm{~min}$. The supernatants were collected after boiling for $5 \mathrm{~min}$. Protein contents were measured using the BCA Protein Assay kit. Proteins $(50 \mu \mathrm{g})$ were separated on $12 \%$ sodium dodecyl sulfate-polyacrylamide gel electrophoresis, and electro-transferred onto nitrocellulose membranes. The membranes were blocked in $5 \%$ non-fat milk at $37^{\circ} \mathrm{C}$ for $1 \mathrm{~h}$, and then incubated with the primary antibodies at $4^{\circ} \mathrm{C}$ overnight. Afterward, the membranes were washed with the TBST buffer (containing $10 \mathrm{mM}$ Tris-HCl, pH 7.6, $150 \mathrm{mM} \mathrm{NaCl}$, and $0.1 \%$ Tween-20) three times, and incubated with the secondary antibodies at $37^{\circ} \mathrm{C}$ for $1 \mathrm{~h}$. Images of the blots were captured, and densitometric analysis was performed using an ImageQuant LAS 500 (Fujifilm, Tokyo, Japan).

Statistical analysis. All values are expressed as mean values or mean values \pm standard derivations from three independent experiments and analyses. Statistical significance between different groups was analyzed by one-way analysis of variance (ANOVA) with Duncan's multiple range tests using the SPSS version 13.0 (SPSS Inc., Chicago, IL, USA). Statistical significance was defined at $\mathrm{P}<0.05$.

\section{Results}

Cytotoxic effect of anpigenin on the cells. In vitro effect of apigenin on the HCT-116 cells is described in Fig. 1. Apigenin exerted cytotoxic effect on the cells, and inhibited cell growth (i.e. decreased cell viability) dose- and time-dependently. Apigenin of $40 \mu \mathrm{M}$ only inhibited cell growth by $9.3-23.1 \%$ when the cells were treated for 24-72 h. Thus this dose was not used in other assays except morphological observation.
However, higher apigenin dose showed higher cytotoxic effect and thereby resulted in lower cell viability (i.e. greater inhibition). If apigenin was used at $160 \mu \mathrm{M}$ and the cells were treated for $72 \mathrm{~h}$, growth inhibition reached to a maximum value of $80.5 \%$. The calculated $\mathrm{IC}_{50}$ values of apigenin with treating times of 24,48 and $72 \mathrm{~h}$ were approximately $98.2,83.3$ and $77.9 \mu \mathrm{M}$, respectively. These data demonstrated clearly that longer treatment time also resulted in apigenin stronger inhibition (i.e. cytotoxic effect) on the cells.

In addition, when the HCT-116 cells were treated with apigenin of various doses, nuclei morphological changes were observed in the treated cells after Hoechst 33258 staining (Fig. 2), especially when apigenin of $160 \mu \mathrm{M}$ was used. High chromatin condensation and visible formation of apoptotic bodies were found in the treated cells (Fig. 2F). This phenomenon indicated that apigenin was able to induce apoptosis besides growth inhibition on the cells.

$G_{0} / G_{1}$ phase cell cycle arrest and apoptosis induction of apigenin. To understand if apigenin had effect on cell cycle progression of the HCT-116 cells, the distribution of the cells in different cell cycle phases was assessed using flow cytometry. Consistent changes in the cell cycle at $24 \mathrm{~h}$ were observed along with increased apigenin doses $(60-160 \mu \mathrm{M})$. In the control cells, the respective portions of $S, G_{0} / G_{1}$ and $G_{2} / M$ phases were 52.2, 25.3 and 21.4\% (Fig. 3). As apigenin dose increased into higher level, the treated cells showed decreasing trend in the portions of both $\mathrm{G}_{2} / \mathrm{M}$ and $\mathrm{S}$ phases but increasing trend in the portion of $G_{0} / G_{1}$ phase. This demonstrated that apigenin was dose-dependent in arresting the cell cycle at $\mathrm{G}_{0} /$ $\mathrm{G}_{1}$ phase.

After $24 \mathrm{~h}$ exposure to apigenin of $60-160 \mu \mathrm{M}$, the cells were collected and detected to show potential apoptosis induction of apigenin. The results shown in Fig. 4 demonstrate that the portion of apoptotic cells (early plus late apoptotic cells) was enhanced with increased apigenin dose. Treatment of the cells with 60-160 $\mu \mathrm{M}$ apigenin caused 5.6, 11.9, 15.5, and 16.7\% Annexin V-FITC positive cells (Fig. 4B-E). However, the control 
A

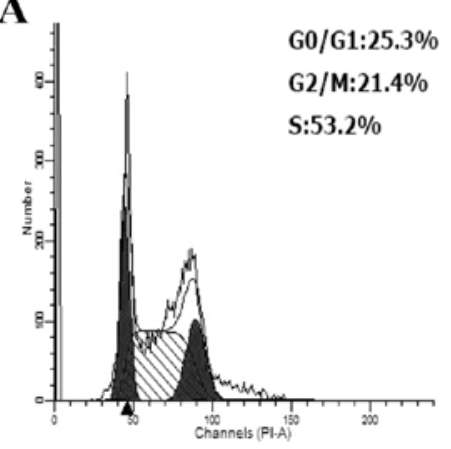

D

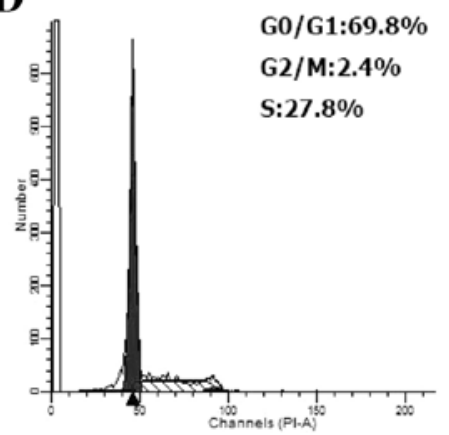

B

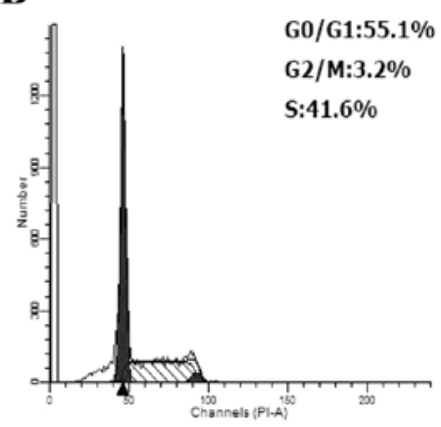

$\mathbf{E}$

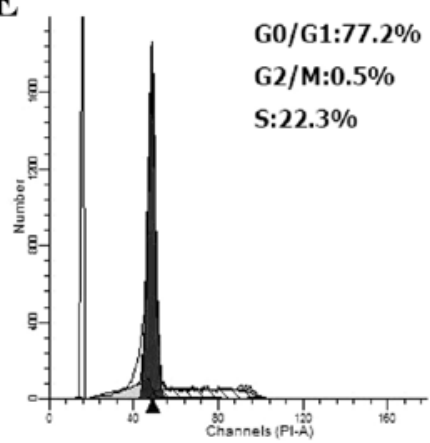

C

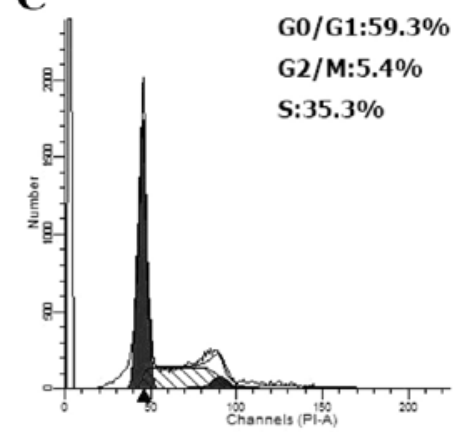

Figure 3. Apigenin disturbed the HCT-116 cells cycle arrest at $\mathrm{G}_{0} / \mathrm{G}_{1}$ phase in a dose-dependent manner. (A-E) represent the control cells, and the cells treated by apigenin at $40,60,80,120$, and $160 \mu \mathrm{M}$, respectively.

A

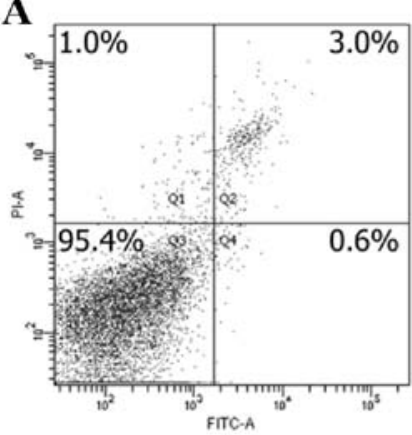

D

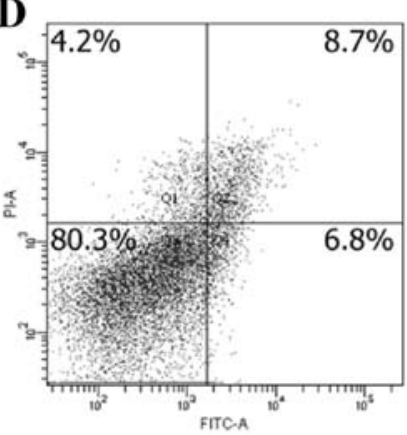

B

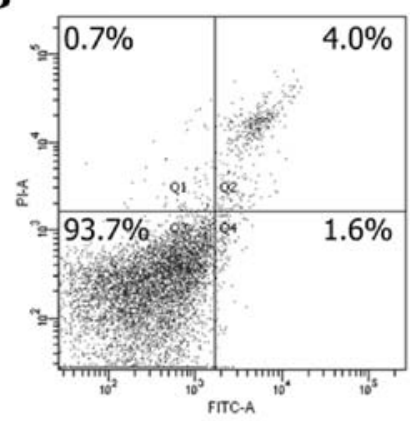

$\mathbf{E}$

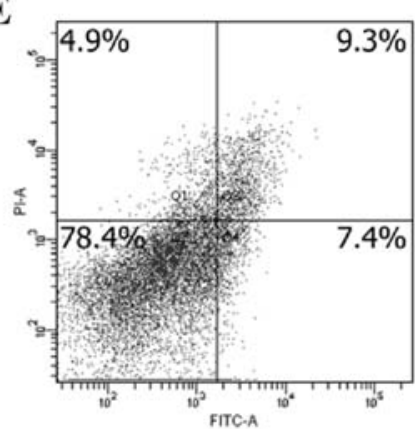

C

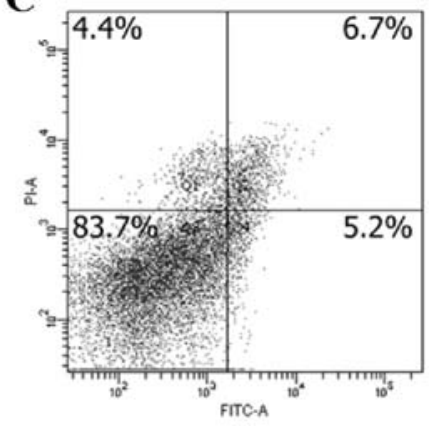

Figure 4. Apoptosis induction of apigenin towards the HCT-116 cells. The cells were exposed to $0.1 \%$ DMSO (A) and apigenin at $60 \mu \mathrm{M}$ (B); $80 \mu \mathrm{M}$ (C); $120 \mu \mathrm{M}(\mathrm{D})$; and $160 \mu \mathrm{M}(\mathrm{E})$, for $24 \mathrm{~h}$, and then the number of cells undergoing apoptosis was detected using Annexin $\mathrm{V}$ staining and flow cytometry.

cells were detected to only have $3.6 \%$ apoptotic cells (Fig. 4A). These results implied that apigenin indeed had apoptosis induction, which was dependent on the used apigenin dose.

Intracellular ROS and $\mathrm{Ca}^{2+}$ as well as MMP loss in response to apigenin treatment. The cells were treated with apigenin of various doses for $24 \mathrm{~h}$, and assayed for their intracellular ROS levels. The results (Fig. 5A) showed that ROS generation in the cells was significantly increased after apigenin exposure. In comparison with the control cells, the cells treated with $160 \mu \mathrm{M}$ apigenin had increased ROS level up to $301.8 \%$. Other three apigenin doses $(60-120 \mu \mathrm{M})$ resulted in the cells with increased 
A

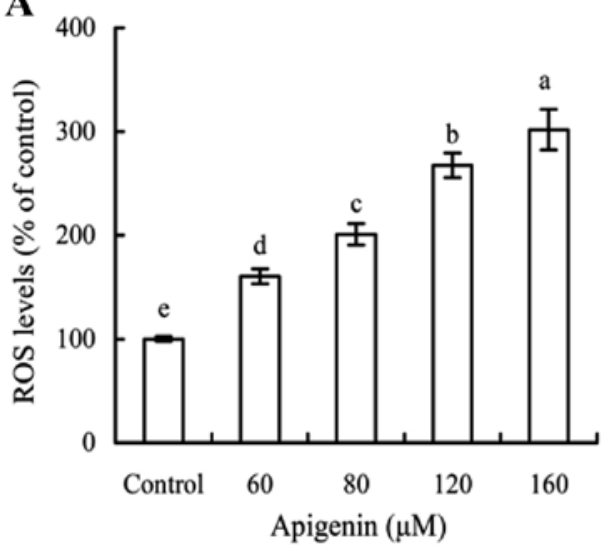

B

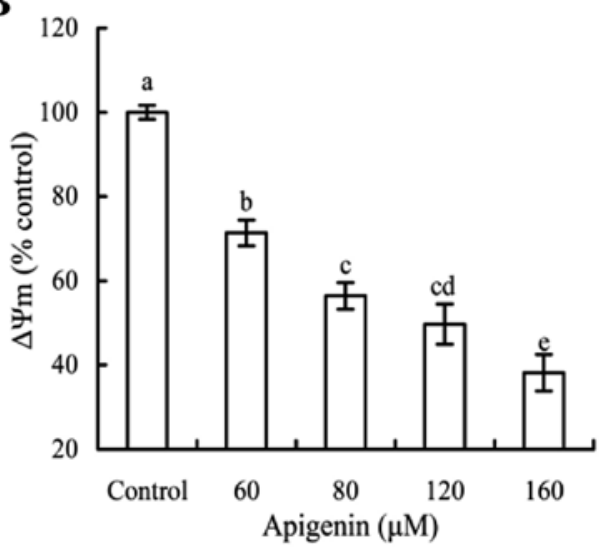

Figure 5. Effects of apigenin doses on intracellular ROS generation (A) and mitochondrial membrane potential loss (B) of the HCT-116 cells. The cells were treated with apigenin for $24 \mathrm{~h}$. Different lowercase letters above the columns indicate significant data differences between different groups $(\mathrm{P}<0.05)$. $\Delta \Psi \mathrm{m}$, mitochondrial membrane potential loss.

ROS levels of 160.5, 200.8 and 267.4\%. Enhancement of ROS generation depended on the used apigenin doses. In addition, the effect of apigenin on MMP loss of the treated cells was also measured. After $24 \mathrm{~h}$ treatment with apigenin of four dose levels, the treated cells showed significant decrease in MMP in comparison with the control cells (Fig. 5B). Apigenin was thus proved able to damage mitochondrial membrane. Moreover, MMP loss of the treated cells was also observed in an apigenin dose-dependent manner. These results pointed out an important fact; that is, apigenin had potential toxic effects on the cells via both mitochondria and ER organelles.

As the results demonstrated in Fig. 6, apigenin at 60-160 $\mu \mathrm{M}$ with treating time of $24 \mathrm{~h}$ caused the treated cells increased intracellular $\mathrm{Ca}^{2+}$ levels in a dose-dependent manner $(\mathrm{P}<0.05)$. Intracellular $\mathrm{Ca}^{2+}$ levels of the treated cells were 117.3, 126.7, 135.1 and $147.4 \%$ of the control cells. These results of $\mathrm{Ca}^{2+}$ release were consistent with those of ROS generation and MMP loss. It is thus verified that higher ROS generation induced ER stress, which consequently resulted in abundant $\mathrm{Ca}^{2+}$ release into the cytosol.

Increased mRNA expression of CHOP and DR5 in the treated cells. Real-time RT-PCR results showed that apgenin at dose levels of 60,120 , and $160 \mu \mathrm{M}$ could upregulate both $\mathrm{CHOP}$ (1.2-, 2.3-, and 3.4-fold) and DR5 (1.1-, 1.5-, and 2.1-fold) mRNA expression in the treated cells (Fig. 7). Higher apigenin dose clearly resulted in greater upregulation of CHOP and DR5. These results proved that apigenin might induce ER stress and activate the death receptor signaling pathway, which should be underlined to reveal the related mechanisms.

Apoptotic mechanism is involved in ROS generation and ER stress. To reveal the underlying mechanism responsible for apigenin-induced apoptosis in the HCT-116 cells, expression levels of these associated proteins were evaluated. The results given in Fig. 8 indicated that apigenin increased protein expression levels of CHOP (1.1-3.5-fold), DR5 (1.2-2.4-fold), cleaved BID (1.1-1.6 fold), cleaved caspase-3 (1.0-1.3-fold), cleaved caspase-8 (1.1-1.6-fold), and cleaved caspase-9 (1.3-1.7-fold) (Fig. 8A), Bax (1.6-3.5-fold), and cytochrome c (1.0-2.2-fold) (Fig. 8B) in the cytosol, but decreased protein expression level

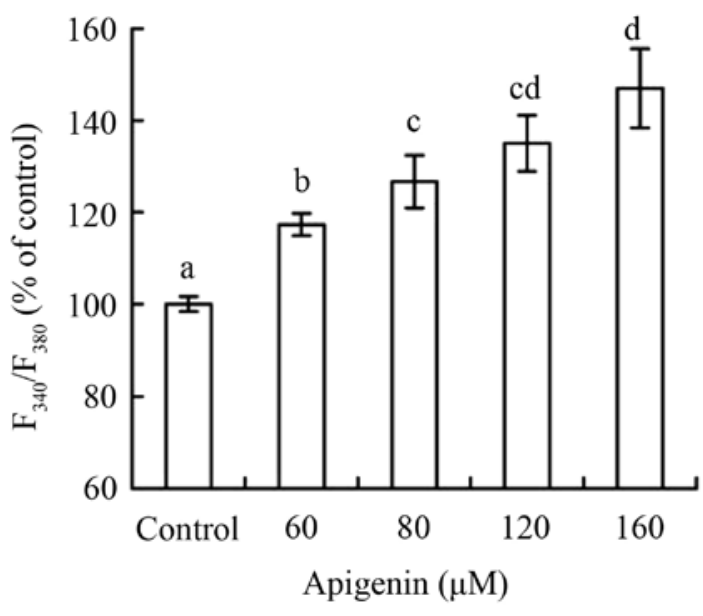

Figure 6. Effects of apigenin doses on intracellular $\mathrm{Ca}^{2+}$ of the HCT-116 cells The cells were treated with apigenin for $24 \mathrm{~h}$, and the data were expressed as fluorescence ratio of $340 / 380 \mathrm{~nm}\left(\mathrm{~F}_{340} / \mathrm{F}_{380}\right)$. Different lowercase letters above the columns indicate significant data differences between the different groups $(\mathrm{P}<0.05)$

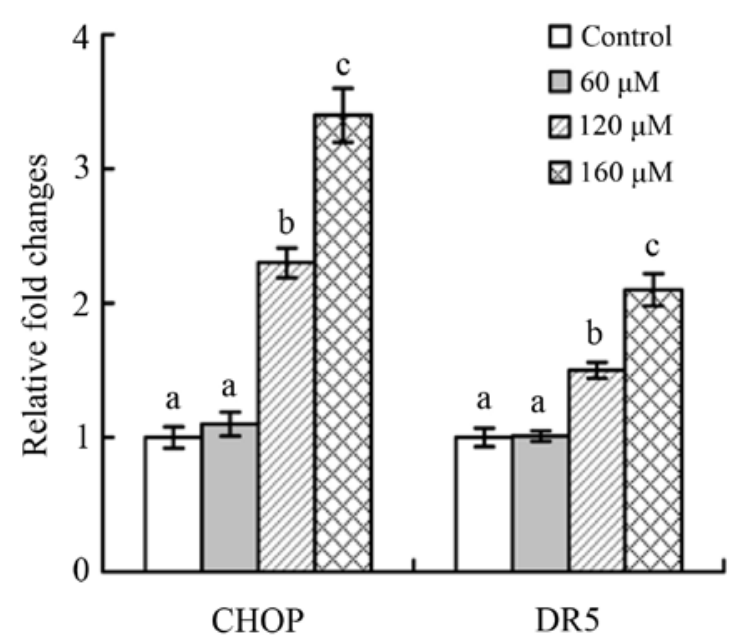

Figure 7. Effects of apigenin doses on mRNA expression of CHOP and DR5 in the HCT-116 cells. The cells were exposed to 0.1\% DMSO (as control), and 60,120 , and $160 \mu \mathrm{M}$ agpigenin for $24 \mathrm{~h}$. Different lowercase letters above the columns indicate significant data differences between the different groups $(\mathrm{P}<0.05)$. 
A
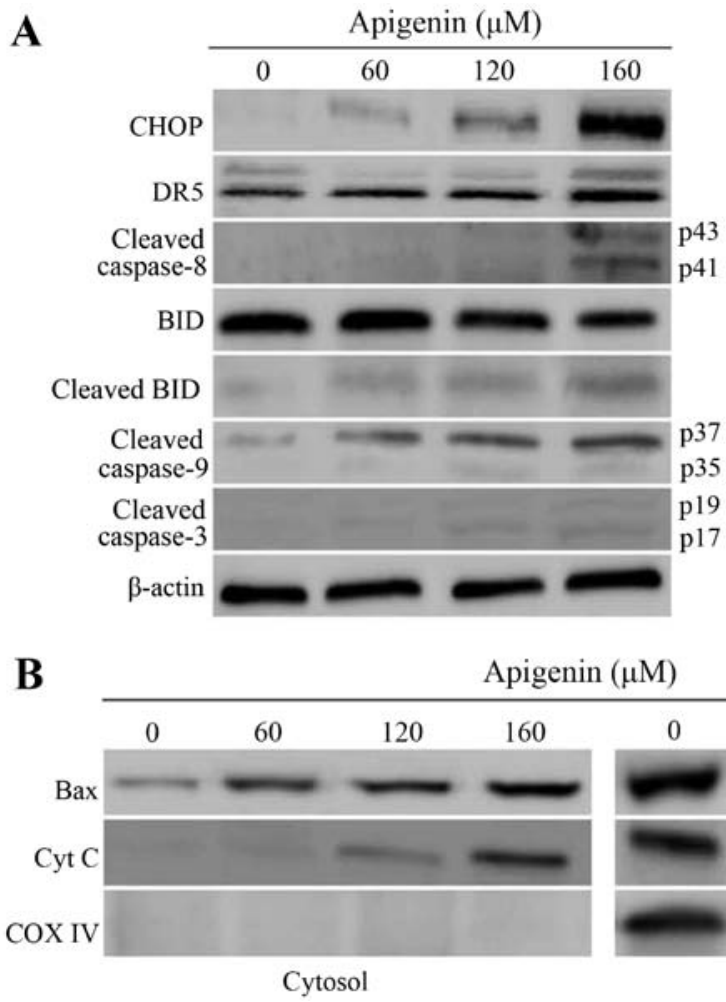

\begin{tabular}{|c|c|c|c|}
\hline 0 & 60 & 120 & 160 \\
\hline 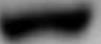 & $\sigma$ & $=$ & $=$ \\
\hline$m$ & $=10$ & reses & \\
\hline
\end{tabular}

Figure 8. Western blotting results for expression levels of the related proteins in the HCT-116 cells exposed to three apigenin doses. The cells were treated with $0.1 \%$ DMSO (control) and 60-160 $\mu \mathrm{M}$ apigenin for $24 \mathrm{~h}$. Apigenin promoted upregulation of CHOP, DR5, cleaved caspase-8, cleaved caspase-9, cleaved caspase-3, cleaved BID, Bax, and cytochrome c (Cyto C).

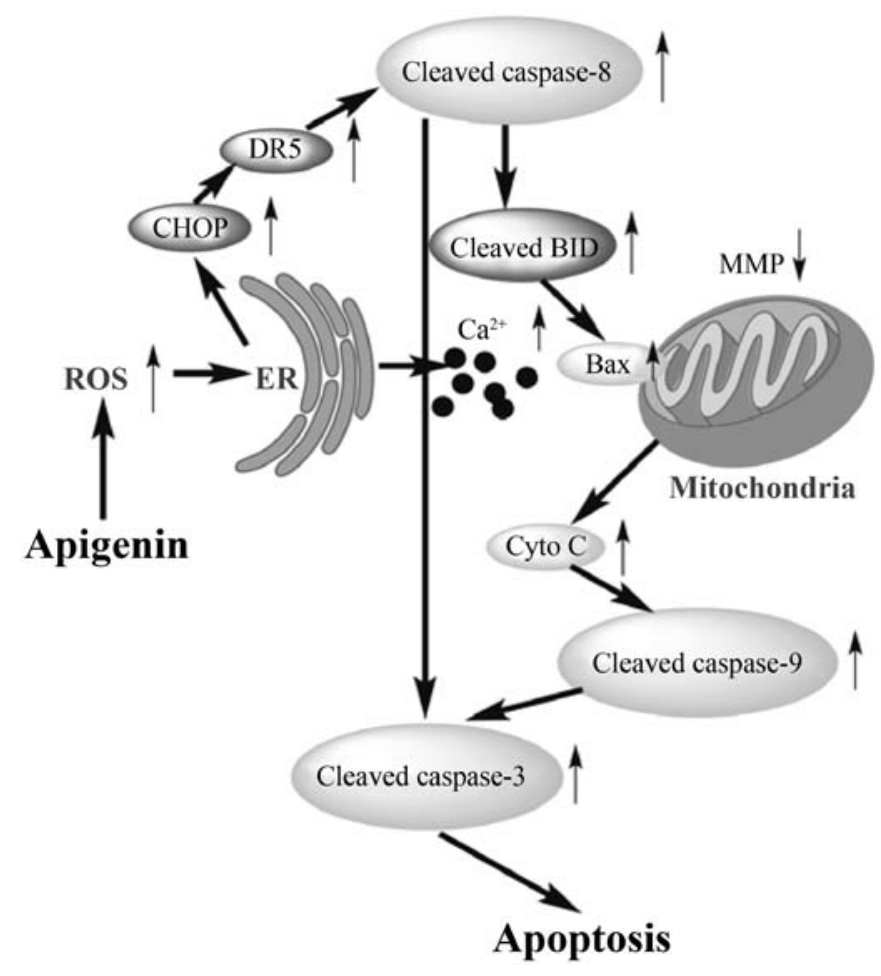

Figure 9. Suggested mechanism and signaling pathways for the apigenininduced apoptosis towards the HCT-116 cells. Cyto C, cytochrome c.

of BID (1.0-2.9-fold) (Fig. 8A). Higher apigenin dose led to greater expression changes of these proteins. Based on these results, it is thus verified that apigenin-induced apoptosis was mediated by ROS generation and ER stress, through upregulating CHOP and DR5 and therefore triggering both extrinsic and intrinsic pathways. A molecular mechanism for the apoptosis induction of apigenin on the cells is outlined in Fig. 9. Apigenin conferred the treated cells with ER stress via greater ROS generation, increased CHOP and DR5 mRNA levels, regulated the expression of these pro-apoptotic proteins (cleaved caspase-3, cleaved caspase-8, and cleaved caspase- 9 , cleaved BID, and Bax), increased cytochrome c release from the mitochondria into the cytosol, and finally initiated apoptosis of the cells.

\section{Discussion}

Several studies have reported that apigenin has anticancer activities via anti-proliferation, angiogenesis and apoptosis induction $(1,27,28)$. The involved mechanisms have also been revealed. Apigenin can inhibit the growth of the HT-29 cells dose- and time-dependently, cause DNA fragmentation, and increase mRNA expression levels of CASP3 (late apoptosis, effector) and CASP8 (early apoptosis, initiator) (29). Apigenin inhibits the proliferation of the T-24 cells, and induces apoptosis via the mitochondrial pathway (30). Apigenin can activate $\mathrm{PKC} \delta$, which then activate caspase pathway to induce apoptosis in the leukemia THP-1 cells (31). Apigenin is capable of inducing apoptosis via a caspase-dependent pathway in the MDA-MB-453 cells as well as inhibiting the well-known JAK2-STAT3-VEGF signaling pathway (32). Apigenin is also able to upregulate DR5 expression in the human acute lymphoblastic leukemic cell line Jurkat, prostate cancer cell line DU145, and colon cancer cell line DLD-1 to 
trigger TRAIL-induced apoptosis (33). In this study, apigenin was also observed to inhibit the growth of the HCT-116 cells, to arrest cell cycle at $\mathrm{G}_{0} / \mathrm{G}_{1}$ phase, to increase both intracellular ROS and $\mathrm{Ca}^{2+}$ levels, and to decrease MMP. Finally, both extrinsic and intrinsic pathways were triggered. Clearly, the outlined apoptotic mechanism involved ROS generation and ER stress in this study is different to those reported mechanisms mentioned above.

In normal cells, apigenin processes anti-oxidation. However, in cancer cells, apigenin exhibits pro-oxidation rather than anti-oxidation $(34,35)$. In this study, intracellular ROS level was suggested to play an important role in the ER stress-mediated signaling pathway. This finding is supported by the results from other studies. Apigenin increases ROS level in the human lung cancer A549 cells, which leads to high $\mathrm{Bax} / \mathrm{Bcl}-2$ ratio to cause mitochondria dysfunction and to trigger caspase-dependent apoptosis (36). Apigenin can block cell cycle progression at $\mathrm{G}_{2} / \mathrm{M}$ stage, increase intracellular ROS production, and therefore cause AKT hypophosphorylation in the triple-negative MDA-MB-468 breast cancer cells (37). In addition, apigenin can trigger intracellular ROS generation, activate mitogen-activated protein kinase (MAPK) ERK1/2 in the human fibroblast-like synoviocyte MH7A cells, and finally cause apoptosis via activation of caspase-3 and -7 (38). These results support that apigenin caused apoptosis induction towards the HCT-116 cells through enhancing ROS generation and resultant ER stress.

The execution of apoptosis is accomplished by caspase family via two major pathways, intrinsic pathway and extrinsic pathway (39). In the intrinsic pathway, cells are stimulated by various toxic compounds, which causes cytochrome c release from the mitochondria into the cytosol. A so-called complex, apoptosome, is thus formed to activate the cleaved caspase- 9 as well as downstream caspases (40). The Bcl-2 protein family contains both anti- and pro-apoptotic members. Bcl-2 and its closest Bcl-xL and Bcl-w, can protect cells from apoptosis, whereas other Bcl-2 relatives (e.g. Bax, Bak and Bok) are proapoptotic proteins (41). Once the $\mathrm{Bax} / \mathrm{Bcl}-2$ ratio increases, apoptosis is induced, resulting in the release of apoptogenic factors from the mitochondria (42). On the contrary, in the extrinsic pathway, the caspases are activated by death receptors such as FAS, TNFR1, DR3, DR4, and DR5 (43). These cell surface proteins recruit adaptor proteins (e.g. FADD) to form a death-inducing signaling complex with procaspase- 8 that induces caspase- 8 activation. Downstream effector caspases (such as caspase-3, -7 and -9) are thus cleaved (44). However, the extrinsic apoptotic pathway has crosstalk with the intrinsic apoptotic pathway via caspase- 8 cleavage of the BID, which then activates the mitochondrial pathway to amplify the apoptotic signal (45).

When the HCT-116 cells were treated with apigenin, they showed decreased MMP and upregulated Bax protein. As a consequence, cytochrome $\mathrm{c}$ was released from the mitochondria to the cytosol, which activated cleaved caspase- 9 and cleaved caspase-3 to induce apoptosis. In addition, accumulation of intracellular ROS led to continuous release of $\mathrm{Ca}^{2+}$ from the ER lumen to the cytosol, which consequently caused ER stress. Overload $\mathrm{Ca}^{2+}$ levels in the cytoplasm accelerated $\mathrm{Ca}^{2+}$ influx into the mitochondria, which resulted in greater ROS generation and finally caused the opening of the permeability transition pore. Increased ROS generation within the mitochondria was thus released, and as a feedback to simulate the $\mathrm{Ca}^{2+}$ release channels on the ER (46). CHOP as protein indicator of ER stress was thus activated to upregulate its downstream protein DR5. DR5 overexpression activated cleaved caspase-8. Cleaved caspase- 8 has two roles: to activate cleaved caspase- 3 and to cleave BID to generate cleaved BID. Cleaved BID in turn induced Bax activation. Thus, the mitochondrial pathway was amplified by the ER stress signaling pathway.

Other studies have assessed apoptosis induction of some natural products, and shown apoptotic mechanism similar to this study. Hesperidin from Citrus seed can induce apoptosis in the human hepatocellular carcinoma HepG2 cells via both mitochondrial and death receptor pathways, evidenced by the upregulation of Bax and Bak protein levels, downregulation of Bcl-xl protein level, and activation of tBID and caspase-3, -8 , and -9 (47). Licochalcone $B$, isolated from the roots of Chinese licorice, exhibits apoptosis induction towards the oral squamous cell carcinoma HN22 and HSC4 cells via increasing ROS levels, as well as CHOP, DR4 and DR5 protein expression (48). Accompanying by upregulation of these apoptotic proteins, expression levels of anti-apoptotic proteins (e.g. Mcl-1) decrease, but pro-apoptotic proteins (e.g. Bax) level is upregulated (48). Emodin, a natural anthraquinone-type compound from Rheum palmatum L, can induce apoptosis in the human cervical cancer HeLa cells (49). In the emodin-treated cells, protein expression levels of cytochrome c, Apaf-1, FAS, FasL, and FADD are all upregulated whilst those levels of procaspase-3, -8 and -9 are all downregulated (49). These findings state that emodin can induce both intrinsic mitochondrial and extrinsic death receptor apoptotic pathways (49), and therefore provide support to the outlined mechanism of this study.

Based on the present results, it is concluded that apigenin is a promising anticancer compound capable of inhibiting proliferation of the colon carcinoma HCT-116 cells, disturbing cell cycle progression to arrest the cells at $G_{0} / G_{1}$ phase, causing abundant intracellular ROS generation and $\mathrm{Ca}^{2+}$ release, destroying mitochondrial membrane, and inducing apoptosis. Apigenin can upregulate the expression of CHOP, DR5, cleaved caspase-3, cleaved caspase-8, and cleaved caspase-9, cleaved BID, and Bax, and can also enhance cytochrome $\mathrm{c}$ release. The outlined apoptotic mechanism is thus, for the first time, suggested to involve ROS-induced and ER stressmediated intrinsic and extrinsic pathways.

\section{Acknowledgements}

This study was funded by the Key Research Project in Science and Technology of the Education Department of Heilongjiang Province (project no. 11551z018).

\section{References}

1. Yang CS, Landau JM, Huang MT and Newmark HL: Inhibition of carcinogenesis by dietary polyphenolic compounds. Annu Rev Nutr 21: 381-406, 2001.

2. Patel D, Shukla S and Gupta S: Apigenin and cancer chemoprevention: Progress, potential and promise (Review). Int J Oncol 30: 233-245, 2007.

3. Li ZD, Hu XW, Wang YT and Fang J: Apigenin inhibits proliferation of ovarian cancer A2780 cells through Id1. FEBS Lett 583: 1999-2003, 2009. 
4. Mak P, Leung YK, Tang WY, Harwood C and Ho SM: Apigenin suppresses cancer cell growth through ERbeta. Neoplasia 8: 896-904, 2006.

5. Wang IK, Lin-Shiau SY and Lin JK: Induction of apoptosis by apigenin and related flavonoids through cytochrome c release and activation of caspase-9 and caspase-3 in leukaemia HL-60 cells. Eur J Cancer 35: 1517-1525, 1999.

6. Xu C, Bailly-Maitre B and Reed JC: Endoplasmic reticulum stress: Cell life and death decisions. J Clin Invest 115: 2656-2664, 2005.

7. Kim R, Emi M, Tanabe K and Murakami S: Role of the unfolded protein response in cell death. Apoptosis 11: 5-13, 2006.

8. Malhotra JD and Kaufman RJ: The endoplasmic reticulum and the unfolded protein response. Semin Cell Dev Biol 18: 716-731, 2007.

9. Oyadomari S and Mori M: Roles of CHOP/GADD153 in endoplasmic reticulum stress. Cell Death Differ 11: 381-389, 2004.

10. Meares GP, Mines MA,BeurelE,Eom TY, Song L,Zmijewska AA and Jope RS: Glycogen synthase kinase-3 regulates endoplasmic reticulum (ER) stress-induced CHOP expression in neuronal cells. Exp Cell Res 317: 1621-1628, 2011.

11. Yamaguchi $\mathrm{H}$ and Wang HG: CHOP is involved in endoplasmic reticulum stress-induced apoptosis by enhancing DR5 expression in human carcinoma cells. J Biol Chem 279: 45495-45502, 2004

12. Gorman AM, Healy SJ, Jäger R and Samali A: Stress management at the ER: Regulators of ER stress-induced apoptosis. Pharmacol Ther 134: 306-316, 2012.

13. Trachootham D, Alexandre J and Huang P: Targeting cancer cells by ROS-mediated mechanisms: A radical therapeutic approach? Nat Rev Drug Discov 8: 579-591, 2009.

14. Fruehauf JP and Meyskens FL Jr: Reactive oxygen species: A breath of life or death? Clin Cancer Res 13: 789-794, 2007.

15. Rigas B and Sun Y: Induction of oxidative stress as a mechanism of action of chemopreventive agents against cancer. Br J Cancer 98: 1157-1160, 2008.

16. Schumacker PT: Reactive oxygen species in cancer cells: Live by the sword, die by the sword. Cancer Cell 10: 175-176, 2006.

17. Trachootham D, Zhou Y, Zhang H, Demizu Y, Chen Z Pelicano H, Chiao PJ, Achanta G, Arlinghaus RB, Liu J, et al: Selective killing of oncogenically transformed cells through a ROS-mediated mechanism by beta-phenylethyl isothiocyanate. Cancer Cell 10: 241-252, 2006.

18. Zou P, Chen M, Ji J, Chen W, Chen X, Ying S, Zhang J, Zhang Z, Liu Z, Yang S, et al: Auranofin induces apoptosis by ROS-mediated ER stress and mitochondrial dysfunction and displayed synergistic lethality with piperlongumine in gastric cancer. Oncotarget 6: 36505-36521, 2015.

19. Shen S, Zhang Y, Zhang R and Gong X: Sarsasapogenin induces apoptosis via the reactive oxygen species-mediated mitochondrial pathway and ER stress pathway in HeLa cells. Biochem Biophys Res Commun 441: 519-524, 2013.

20. Shin SY, Lee JM, Lee MS, Koh D, Jung H, Lim Y and Lee YH: Targeting cancer cells via the reactive oxygen species-mediated unfolded protein response with a novel synthetic polyphenol conjugate. Clin Cancer Res 20: 4302-4313, 2014.

21. Chen CY, Yiin SJ, Hsu JL, Wang WC, Lin SC and Chern CL: Isoobtusilactone A sensitizes human hepatoma Hep G2 cells to TRAIL-induced apoptosis via ROS and CHOP-mediated up-regulation of DR5. J Agric Food Chem 60: 3533-3539, 2012.

22. Johnson JL and Gonzalez de Mejia E: Interactions between dietary flavonoids apigenin or luteolin and chemotherapeutic drugs to potentiate anti-proliferative effect on human pancreatic cancer cells, in vitro. Food Chem Toxicol 60: 83-91, 2013.

23. Salvioli S, Ardizzoni A, Franceschi C and Cossarizza A: JC-1, but not DiOC6(3) or rhodamine 123, is a reliable fluorescent probe to assess delta psi changes in intact cells: Implications for studies on mitochondrial functionality during apoptosis. FEBS Lett 411: 77-82, 1997.

24. Boissy RE, Trinkle LS and Nordlund JJ: Separation of pigmented and albino melanocytes and the concomitant evaluation of endogenous peroxide content using flow cytometry. Cytometry 10: 779-787, 1989.

25. Vega A, Chacón P, Monteseirín J, El Bekay R, Alba G, Martín-Nieto J and Sobrino F: Expression of the transcription factor NFAT2 in human neutrophils: IgE-dependent, $\mathrm{Ca}^{2+}-$ and calcineurin-mediated NFAT2 activation. J Cell Sci 120 2328-2337, 2007.

26. Livak KJ and Schmittgen TD: Analysis of relative gene expression data using real-time quantitative PCR and the $2^{-\Delta \Delta C T}$ method. Methods 25: 402-408, 2001.
27. Van Dross R, Xue Y, Knudson A and Pelling JC: The chemopreventive bioflavonoid apigenin modulates signal transduction pathways in keratinocyte and colon carcinoma cell lines. J Nutr 133 (Suppl 1): S3800-S3804, 2003.

28. Shukla S and Gupta S: Dietary agents in the chemoprevention of prostate cancer. Nutr Cancer 53: 18-32, 2005.

29. Turktekin M, Konac E, Onen HI, Alp E, Yilmaz A and Menevse S: Evaluation of the effects of the flavonoid apigenin on apoptotic pathway gene expression on the colon cancer cell line (HT29). J Med Food 14: 1107-1117, 2011.

30. Shi MD, Shiao CK, Lee YC and Shih YW: Apigenin, a dietary flavonoid, inhibits proliferation of human bladder cancer T-24 cells via blocking cell cycle progression and inducing apoptosis. Cancer Cell Int 15: 33-45, 2015.

31. Vargo MA, Voss OH, Poustka F, Cardounel AJ, Grotewold E and Doseff AI: Apigenin-induced-apoptosis is mediated by the activation of PKCdelta and caspases in leukemia cells. Biochem Pharmacol 72: 681-692, 2006.

32. Seo HS, Ku JM, Choi HS, Woo JK, Jang BH, Shin YC and Ko SG: Induction of caspase-dependent apoptosis by apigenin by inhibiting STAT3 signaling in HER2-overexpressing MDA-MB-453 breast cancer cells. Anticancer Res 34: 2869-2882, 2014

33. Horinaka M, Yoshida T, Shiraishi T, Nakata S, Wakada M and Sakai T: The dietary flavonoid apigenin sensitizes malignant tumor cells to tumor necrosis factor-related apoptosis-inducing ligand. Mol Cancer Ther 5: 945-951, 2006.

34. Miyoshi N, Naniwa K, Yamada T, Osawa T and Nakamura Y: Dietary flavonoid apigenin is a potential inducer of intracellular oxidative stress: The role in the interruptive apoptotic signal. Arch Biochem Biophys 466: 274-282, 2007.

35. Andueza A, García-Garzón A, Ruiz de Galarreta M, Ansorena E, Iraburu MJ, López-Zabalza MJ and Martínez-Irujo JJ: Oxidation pathways underlying the pro-oxidant effects of apigenin. Free Radic Biol Med 87: 169-180, 2015.

36. Lu HF, Chie YJ, Yang MS, Lee CS, Fu JJ, Yang JS, Tan TW, Wu SH, Ma YS, Ip SW, et al: Apigenin induces caspasedependent apoptosis in human lung cancer A549 cells through Bax- and Bcl-2-triggered mitochondrial pathway. Int J Oncol 36: 1477-1484, 2010.

37. Harrison ME, Power Coombs MR, Delaney LM and Hoskin DW: Exposure of breast cancer cells to a subcytotoxic dose of apigenin causes growth inhibition, oxidative stress, and hypophosphorylation of Akt. Exp Mol Pathol 97: 211-217, 2014.

38. Shin GC, Kim C, Lee JM, Cho WS, Lee SG, Jeong M, Cho J and Lee $\mathrm{K}$ : Apigenin-induced apoptosis is mediated by reactive oxygen species and activation of ERK1/2 in rheumatoid fibroblastlike synoviocytes. Chem Biol Interact 182: 29-36, 2009.

39. Hale AJ, Smith CA, Sutherland LC, Stoneman VE,Longthorne VL, Culhane AC and Williams GT: Apoptosis: Molecular regulation of cell death. Eur J Biochem 236: 1-26, 1996.

40. Wang $\mathrm{C}$ and Youle RJ: The role of mitochondria in apoptosis. Annu Rev Genet 43: 95-118, 2009.

41. Inoue S, Browne G, Melino G and Cohen GM: Ordering of caspases in cells undergoing apoptosis by the intrinsic pathway. Cell Death Differ 16: 1053-1061, 2009.

42. Cory S, Huang DCS and Adams JM: The Bcl-2 family: Roles in cell survival and oncogenesis. Oncogene 22: 8590-8607, 2003.

43. Ashkenazi A: Targeting the extrinsic apoptosis pathway in cancer. Cytokine Growth Factor Rev 19: 325-331, 2008.

44. Nagata S: Apoptosis by death factor. Cell 88: 355-365, 1997.

45. Wang X: The expanding role of mitochondria in apoptosis. Genes Dev 15: 2922-2933, 2001.

46. Berridge MJ: The endoplasmic reticulum: A multifunctional signaling organelle. Cell Calcium 32: 235-249, 2002.

47. Banjerdpongchai R, Wudtiwai B, Khaw-On P, Rachakhom W, Duangnil $\mathrm{N}$ and Kongtawelert P: Hesperidin from Citrus seed induces human hepatocellular carcinoma HepG2 cell apoptosis via both mitochondrial and death receptor pathways. Tumour Biol 37: 227-237, 2016.

48. Oh H, Yoon G, Shin JC, Park SM, Cho SS, Cho JH, Lee MH, Liu K, Cho YS, Chae JI, et al: Licochalcone B induces apoptosis of human oral squamous cell carcinoma through the extrinsicand intrinsic-signaling pathways. Int J Oncol 48: 1749-1757, 2016.

49. Yaoxian W, Hui Y, Yunyan Z, Yanqin L, Xin G and Xiaoke W: Emodin induces apoptosis of human cervical cancer heLa cells via intrinsic mitochondrial and extrinsic death receptor pathway. Cancer Cell Int 13: 71-78, 2013. 